\title{
THE REGISTRATION AND THE DEPRECIATION OF YOUNG TREE PLANTATIONS AND VINEYARDS
}

\author{
Lecturer PhD Student Attila Szora TAMAS, attacosulting@yahoo.com \\ Asistant PhD Student Iulian Bogdan DOBRA, diby_ec@yahoo.com \\ „1 Decembrie 1918” University Alba Iulia
}

\begin{abstract}
This article wants to promote a point of view concerning the registration and accounting procedures, the amortization calculation and the deduction of the expenses' procedures regarding the amortization for young tree plantations and vineyards, in light of the national and international accounting and fiscal regulations.
\end{abstract}

\section{Specific regulations regarding the depreciation of the frozen capital in tangible and intangible assets}

Law no. 15 from March 24, $1994^{1}$ regarding the depreciation of the frozen capital in tangible and intangible assets stipulates at article 1 the following:

Excerpt from the law: "Article 1: The unities that carry economic activities, named economic agents and that immobilize capital in tangible and intangible assets that are depreciating, will calculate, record in accounting books and recuperate the physical and moral wear and tear by its using or in time in order to restore the hired capital".

Also Article 2 mentions: "The depreciating frozen capital is reflected in the patrimony of the economic agents through the goods and values destined to serve the activity on a period of more than a year and that gradually is consumed".

Article 11 specifies: the depreciation of the fixed assets is calculated beginning with the following month from the starting point of the functioning until the integral entry value is recuperated, in conformance with the normal durations of functioning.

Consequently you can see that Law 15/1994 states with value of principle the moment from which the calculation of the depreciating is starting, respectively: the following month from the starting point of functioning.

The Government Decision no. 909 from December 29/1997² regarding the approval of the Methodological Standards of Applying Law no. 15/1994 regarding the depreciation of the frozen capital in tangible and intangible assets stipulates:

Excerpt (text brought up to date until October $1^{\text {st }}, 2000$ ): paragraph 3 specifies the following: "The depreciating frozen capital is reflected in the patrimony of the economic agents, of the legal persons without a lucrative aim and of the individual persons and associations without a legal status that carry activities with the purpose to have incomes and is materialized through the goods and values destined to serve the activity on a period of more than a year and that gradually is consumed".

\footnotetext{
${ }^{1}$ Law 15 from March 24/1994 regarding the depreciation of the frozen capital in tangible and intangible assets Republished in the Official Gazette no. 242/31.05.1991, Part 1

${ }^{2}$ G.D. no. 909/29.12.1997 regarding the approval of the Methodological Standards of applying Law no. 15/1994 regarding the depreciation of the frozen capital in tangible and intangible assets - Published in O.G. no. 4/08.01.1998, Part 1 and modified with G.D. no. 586/2000, and G.D. no. 22/2003
} 
Paragraph 7 states: the goods mentioned in article 4 are assimilated to the fixed assets and are subdue to depreciation the following way: the capacities that are partially working and were not registered as fixed assets, are included in the group in which they will be registered as fixed assets at the value resulted by summing up the their expenses. When being put in function, at the final receipt the depreciation will be determined depending on the final value, and the unamortized value will be recuperated till the end of the normal using duration.

Paragraph 9 refers to the fact that: "Young plantations and protection plantations that are included in group 5 of fixed assets "Animals and plantations", subgroup "Plantations" are exempted from the depreciating calculus and from introducing it in the running expenses", as follows:

- until going on fruits, for young plantations;

- $\quad$ the first 5 years, for protection plantations.

The normal using durations for young plantations and for protection plantations are also mentioned: these durations also include the exemption durations for which the adherent depreciation is not included in the running costs. In this case, the medium yearly depreciation rate is determined depending on the reduced using normal duration, with the exemption period, in years, for which depreciation is not calculated.

Paragraph 12 states: through the entry value of the fixed assets we understand: "in the case of the investments placed in function partially or totally and which were not registered as fixed assets, the entry value is the value set through the working situations at the starting date".

Annex no. 3 to the methodological standards presents the monograph regarding the reflecting in the accountancy of the operations tied to the depreciation of the fixed assets and their putting off function:

The registering in the accountancy of the investments made in own administration, set in functioning partially, which were not registered as fixed assets (point 7 lit. $b$ from the methodological standards) is done the following way:

a) The registering of the partially functioning investment:

231

"On course tangible "

fixed assets" analytically

"Tangible fixed assets without

registering papers as fixed assets"
722

Income from the tangible

fixed assets production"

b) The registering of the depreciation of the investment without registering papers as fixed assets:
6811
"Running expenses
regarding the depreciation
$=281$
"Depreciations regarding the tangible fixed assets" analytically "The depreciation of the
of the fixed assets"
fixed assets without registering papers"

c) The registering of the finished investments that were passed in the fixed assets category:

212

281

"Depreciations regarding the tangible fixed assets analytically

"The depreciations of the tangible fixed assets

without registering papers"
231

281

"Depreciations regarding

the tangible fixed assets 
In conclusion the young tree plantations and the vineyards meet the conditions imposed by the G.D. 909/1997 to be included as depreciating frozen capitals. G.D. 909/1997 and Law no. $15 / 1994$ state that even capacities put in function only partially and which were not registered as fixed assets can be depreciated. The normal utilization periods of the young plantations also include the period until going on fruits, so it is understood the fact young plantations are registered as fixed assets at the date of the investment's realization and reception, and not at the date when the investment goes on fruit.

\section{Specific regulations regarding the accountancy of the frozen capital in tangible and intangible assets}

The P.F.M. Order no. 1.752 from November $17 / 2005^{3}$ regarding the approval of the accountant regulations in concordance with the European norms, makes a reference to the evaluation of the fixed assets as follows:

Excerpt from the Order: Basic evaluation rules mentioned at point 64, paragraph 1 - The fixed assets are assets that generate benefits and are hold for more than a year. They must be evaluated at the acquisition cost or at the production cost. Paragraph 2 - The future economic benefits represent the potential to contribute, direct or indirect, to the treasury flow or the treasury equivalent to the entity.

Consequently, the acknowledgement and the evaluation of the fixed assets (including young plantations) have at their base the existence of future economic benefits (potential) and not mandatory benefits (immediate) - a very important aspect in recognizing the fixed assets. This condition is acknowledged also by the international standard of accountancy no. 41 "Agriculture" as will be seen.

\section{Fiscal regulations regarding the depreciation of the frozen capital in tangible and intangible assets}

Law no 571 from December $22 / 2003^{4}$ regarding the Fiscal code presents a series of aspects about the depreciation of the frozen capital in tangible and intangible assets, as follows:

Excerpt: Chapter 2 - The calculus of the taxable profit

+ article 19 General rules: The taxable profit is calculated as a difference between the income from any source and the running costs, from a fiscal year.

$\rightarrow$ article 21 Expenses: in order to determine the taxable profit, we consider deductible expenses only the expenses made to obtain taxable incomes, including the ones regulated by the normative documents into effect;

article 24 Fiscal depreciation:

$>$ paragraph 11 specifies that Fiscal depreciation is calculated as follows: starting with the following month after the fixed asset is put in function;

$>$ paragraph 12: the tax payers who invest in depreciating fixed assets or in depreciating invention patents, destined for the activities for which they are authorized and which don't apply the accelerated depreciating procedure, can deduct the depreciating expenses with $20 \%$ from their entry value. The remained value to be recuperated on the normal period of utilization is determined after the subtraction from the entry value of the sum equal to the

\footnotetext{
3 P.F.M Order no 1752/17.11.2005 regarding the approval of the accountant regulations in concordance with the European norms, published in O.G. no. 1080/31.11.2005, part 1 and modified with the P.F.M.G. no. 2001/2006

${ }^{4}$ Law no 571/22.12.2003 regarding the Fiscal code, published in O.G. no. 927/23.12.2003, part 1, rectified in O.G. no.

112/06.02.2004 and modified ulterior through 21 normative documents
} 
$20 \%$ deduction. For the animals and plantations acquisitions, the $20 \%$ deduction is granted as follows:

a) for animals, at the acquisition date;

b) for plantations, at the final reception date at the founding of the plantation

We must mention that the above stipulations regarding the fiscal depreciation are the only stipulations in the field, considering that the stipulations of Law no. 15/1994 are no longer possible to apply, with the exception of article 3 paragraph 2 let. a) and of article 8 - without any relevance on this presentation, as it can be seen from their wording:

Excerpt: (22) the stipulations of Law 15/1994 regarding the depreciation of the frozen capital in tangible and intangible assets, republished, with subsequent modifications and completions, are not applied to the calculus of the taxable profit, with the exception of the stipulations in article 3 paragraph 2 letter a) and of article 8 from the same law:

Article 3 mentions: we consider a fixed asset the object or the group of objects that are used as such and follow these conditions:

a) has a higher entry value than the limit set through a government decision. This value can be updated every year, depending on the inflation index;

b) has a normal utilization period of more than a year.

Article 8 stipulates: the normal functioning periods and the classification of the fixed assets are approved by a government decision. At their determination the following will be taken into account: the technical and economic parameters set by the designers and by the producers in the books or technical documentation of the respective fixed assets. The effects of the moral wear and tear will also be taken into account. These periods will be revised periodically, but no later than 5 years.

We wish to mention that although the fiscal code doesn't have anymore the possibility to depreciate in an accelerate manner the plantations (this stipulation was modified in article 1 from the Law no. $163 / 2005^{5}$ ), it is important to know that when this facility was applied, the $20 \%$ deduction for depreciation was applied at the final reception date at THE FOUNDING of the plantation - an important argument (but not the only one) in formulating this article's conclusions.

In conclusion there is no legal impediment in the Fiscal code that will prevent the registering of the young plantations' depreciation as fiscal deductible expenses. The main condition for starting the calculus and the depreciation's deduction from a fiscal point of view is the following: starting with the following month after the depreciable fixed asset in put in function.

\section{Regulations specific to the domain}

Law no. 244 from April 29/2005 ${ }^{6}$ - the law of the vineyard and the wine in the system of the joint organization of the vine market stipulates at article 12 the following: planting means definitively fixing the grafted, deeply rooted vine or portions of vines, with the purpose to produce grapes, grafted cords and father plants.

Consequently Law no. 244 from 29/2002 regulates what the accountant and fiscal legislation haven't established, like the moment when the investment is achieved. That moment happens when there is a definitive fixing of the grafted, deeply rooted vine or the portions of vines, with the purpose to produce grapes, and not in the moment when the plantation is going on fruit (a moment that is quite relative).

\footnotetext{
${ }^{5}$ Law no. 163/01.06.2005 regarding the approval of the Emergency Government Order no. 138/2004 for the modification and the completion of Law no. 571/2003 regarding the Fiscal code, published in O.G. no. 466/01.06.2005, part 1

${ }^{6}$ Law no. 244/2002 - the law of the vineyard and the wine in the system of the joint organization of the vine market, published in the Oficial Gazette no. 333/20.05.2002, part 1, republished in the O.G. no. 633/14.09.2007, part 1
} 
Law no. 348 from July $10 / 2003^{7}$ - the law of the fruit farming - the fruit growing patrimony is classified in the following categories:

$>$ young plantations, until going on fruit;

$>$ plantations on fruits, in full production;

$>$ plantations on fruits, in decline;

$>$ fruit farming seed beds;

$>$ pomological collections, breeding for contests and experimental batches;

$>$ fields in preparation for future plantations;

The time life for the tree and fruit shrubs plantations in normal exploitation conditions and the methods of clearing a plantation are stipulated in the methodological norms of applying the law mentioned above.

Chart no. 1 The time life for tree fruits, fruits shrubs and strawberries plantations.

\begin{tabular}{|l|l|}
\hline \multicolumn{1}{|c|}{ The name of the plantations } & \multicolumn{1}{c|}{ Years } \\
\hline Classic plantations of apple, pear, plum, quince, almond and chestnut trees & 30 \\
\hline Classic plantations of sweet cherry, cherry, peach, hazel and apricot trees & 20 \\
\hline Intensive plantations of apple, pear and plum trees & 20 \\
\hline Intensive plantations of sweet cherry, peach and apricot trees & 20 \\
\hline Walnut trees plantations & 40 \\
\hline Plantations of gooseberry, red currant and jam roses & 10 \\
\hline Plantations of raspberry, blueberry, bramble, elder and other fruit shrubs & 10 \\
\hline Strawberries plantations & 4 \\
\hline
\end{tabular}

Consequently we can say that in the normal time life for plantations are included the periods of existence for young plantations too.

\section{The International Accounting Standard 41 - Agriculture}

Excerpt: IN1. IAS 41 prescribes accounting treatments, the presentations of financial situations and of information related to agricultural activities; a subject that was never approached in other Standards.

IN3. IAS 41 Demands that an entity evaluates that biological asset at its cost, minus any accumulated depreciation and any loss from depreciation.

IN4. IAS 41 A seed bed that applies the historic cost for the accounting of a transaction model may not report profit until the first harvest and sale, probably 30 years after planting. On the other hand, by applying an accounting model that recognizes and evaluates the biological transformation by using the current fair value reports the modifications of the biological transformation on the entire period from planting to harvesting.

IN7. IAS 41 comes into force for the financial situations afferent to the starting periods from January $1^{\text {st }}, 2003$. It is recommended to apply this Standard before this date.

Aria of applicability:

1. This Standard will be applied for the accounting of the following elements, when they refer to agricultural activities:

* biological assets;

* the agricultural production at harvest point and

* Governmental grants.

The chart below offers examples of biological assets; agricultural produce and products resulted after the processing of the harvest:

\footnotetext{
${ }^{7}$ Law no. 348/10.07.2003 - the law of the fruit farming, published in the Official Gazette no. 541/28.07.2003, part I
} 


\section{Chart no. 2 biological assets, agricultural produce and products resulted after processing}

\begin{tabular}{|l|l|l|}
\hline \multicolumn{1}{|c|}{ Biological assets } & $\begin{array}{l}\text { Agricultural } \\
\text { produce }\end{array}$ & $\begin{array}{c}\text { Products resulted after } \\
\text { processing }\end{array}$ \\
\hline Sheep & Wool & Plies, carpets \\
\hline Trees from a plantation & Logs & Lumber \\
\hline Plants & Cotton & Clothes \\
\cline { 2 - 3 } & Sugar cane & Sugar \\
\hline Milk cows & Milk & Cheese \\
\hline Pigs & Carcass & Sausages, processed ham \\
\hline Shrubs & Leafs & Tea, processed tobacco \\
\hline Vine & Grapes & Wine \\
\hline Fruit trees & Fruits & Processed fruits \\
\hline
\end{tabular}

\section{Definitions}

\section{Agriculture - conex definitions}

The following terms are used in this Standard:

A biological asset is a living animal or a plant.

Biological transformation comprises the processes of growth, degeneration, production, and procreation that cause qualitative or quantitative changes in a biological asset

A group of biological assets represent the group of living animals or similar plants.

As a result of the biological transformation we have the following type of products: modifications of the assets through:

$\rightarrow$ growth (quantity increase or quality improvement of an animal or plant);

- deterioration (a drop in quantity or a quality deterioration of an animal or plant);

- reproduction (creating live animals or additional plants);

$\boldsymbol{*}$ or producing agricultural products like latex, tea, wool or milk.

\section{Acknowledgement and evaluation}

An entity will acknowledge a biological asset or an agricultural product only when:

프 the entity controls the asset as a result of the previous events;

it is possible for the entity to obtain future economic benefits associated to the asset;

the fair value or the cost of the asset can be evaluated in a believable way.

In the agricultural activity control can be underlined, for example, by the ownership of cattle, their marking or their marking at acquisition, birth or wean. The future benefits are usually evaluated by measuring the important physical attributes.

A biological asset can be evaluated at the initial acknowledgment and at every date of the balance at a fair value minus the estimated costs at the selling point, with an exception when the fair value can't be evaluated in a believable way.

In order to determine the cost, the accumulated depreciation and the loss from the accumulated depreciation, an entity applies IAS 2 Inventories, IAS 16 Tangible fixed assets and IAS 36 Impairment of Assets. .

\section{Information presentation}

\section{The entity will offer a depiction of each biological asset group.}

An entity is encouraged to offer a quantified depiction of each biological asset group. The entity distinguishes between the biological wasting assets and biological reproduction assets, or between mature and immature biological assets. For example, an entity can present by groups the accountable values of biological wasting assets and biological reproduction assets. Further more, an entity can split those accountable values in mature and immature assets. These distinctions offer 
information that can be useful in evaluating the moments when future cash flows will appear. An entity presents the reasons behind these distinctions.

The biological wasting assets are the assets that are to be harvested as agricultural produce or sold as biological assets. Biological wasting assets are, for example, animals destined for the meat production, animals saved for sale, fish from piscicultural farms and crops like corn, wheat and trees grown for lumber.

The biological reproduction assets are the assets that are not biological wasting assets. For example, milk animals, vine, fruit trees and trees grown for wood fire (uncut trees). The biological reproduction assets are not agricultural produce, but are regenerating.

Biological assets can be classified as mature or as immature biological assets. The mature biological assets are the ones that acquired harvesting characteristics (for the wasting assets) or are suitable for periodical harvests (for the reproduction assets).

If the entity evaluates the biological assets at their cost minus the accumulated depreciation and the loss from the accumulated depreciation at the end of the period, than the entity will present for these kinds of biological assets:

* Depiction of the biological assets;

* An explanation for the reason why the fair value can't be evaluated in a believable way;

* If it's possible, the estimation period when it is possible to learn the fair value;

* The used depreciation method;

* The useful live cycles or the used depreciation rates; and

* The gross book value and the accumulated depreciation (aggregated with the losses from the cumulated depreciation) at the beginning and at the end of the period.

\section{Example 1: XYZ SRL Dairy}

\section{Chart no. 3 Balance}

\begin{tabular}{|l|l|l|l|}
\hline XYZ SRL Dairy & Notes & December 31 & December 31 \\
\hline Balance & & $\mathbf{2 0 X 1}$ & $\mathbf{2 0 X 0}$ \\
\hline ASSETS & & & \\
\hline Frozen assets & & & \\
\hline Milk animals - immature & & 52.060 & 47.730 \\
\hline Milk animals - mature & & 372.990 & 411.840 \\
\hline Subtotal - biological assets & & 425.050 & 459.570 \\
\hline Tangible fixed assets & & 1.462 .650 & 1.409 .800 \\
\hline Total - frozen assets & & $\mathbf{1 . 8 8 7 . 7 0 0}$ & $\mathbf{1 . 8 6 9 . 3 7 0}$ \\
\hline Current assets & & & \\
\hline Inventories & & 82.950 & 70.650 \\
\hline Commercial and other nature claims & & 10.000 & 65.000 \\
\hline Cash & & $\mathbf{1 8 0 . 9 5 0}$ & 10.000 \\
\hline Total current assets & & $\mathbf{2 . 0 6 8 . 6 5 0}$ & $\mathbf{1 4 5 . 6 5 0}$ \\
\hline Total assets & & & \\
\hline
\end{tabular}

An entity is encouraged, but not obliged, to offer a quantified depiction of each biological asset group. The entity distinguishes between the biological wasting assets and biological reproduction assets, or between mature and immature biological assets. An entity presents the reasons behind these distinctions. 


\section{Main operations and activities}

XYZ SRL Dairy is engaged in milk production and delivering to different clients. At December 31, 20X1, the company owned 419 cows for milk (mature assets) and 137 young cows raised for milk (immature assets). The company produces $157.584 \mathrm{~kg}$ of milk with a fair value minus the estimated cost at the selling point of 518.240 (which is determined at the time of the milking) during the financial period which was closed at December 31, $20 \mathrm{X} 1$.

In conclusion: young plantations are acknowledged as biological assets from the moment of their realization, and are presented in the balance in the fixed assets category.

\section{The International Accounting Standard $16^{8}$ - PROPRIETY, PLANT AND EQUIPMENT}

Definition: the fixed assets are the assets used in the production activity. They have physical consistency, are relative on long term and offer future benefits that can be measure in a believable way.

Consequently, we can say young plantations fulfill also the criteria for acknowledgement from IAS 16 like the fixed assets, meaning they are based on ensuring future, not immediate benefits (is mandatory in the current financial period).

The National Accounting Standard 6 of the Moldova Republic - "The accountancy particularities at agricultural enterprises". According to the definitions used by this standard, mature biological assets are the assets that ensure the obtaining of agricultural produce and/or of supplementary biological assets (their regulate harvesting). The immature biological assets are the biological assets that don't ensure the obtaining of the agricultural produce and/or of the supplementary biological assets.

Regarding the ascertaining of the biological assets this standard mentions that the biological asset is established as an asset when:

a) there is sufficient certitude that in the future the enterprise will get an economic advantage from using it;

b) the asset's value can be determined with certitude.

The criteria above are complied when the asset is capable of generating in the future the expected economic advantages and the enterprise plans the activity that allows their obtainment. The size of the expected advantages is determined by taking into account the physical state of the biological asset: cow pregnancy, healthy buds, the germinal state of the seeds, the sown field state, the live stock and the fatting category of the cattle, etc. Based on the data about the physical state we establish the market price for the biological assets.

The enterprise can plan to obtain economic advantages from using the biological assets when it controls them legally, which means the enterprise owns the propriety rights over the assets or they are registered in documents as leased assets.

The criteria presented at letter b) is feasible, from the point of view of this standard, when the enterprise can determine the exact value of the biological asset on the basis of the primary documents and on the basis of the respective account books.

Further more, like the regulator in our country, according to N.A.S. 5 "The financial reports presentation", the enterprise envelops the main particularities of the basic activity in a quantity expression, as follows:

* The biological assets groups and its' components (types of animals and their number in the group, perennial plantations' types and the hectare area);

* The activity's nature and the biological assets' groups;

* The maturity level of each biological asset group;

\footnotetext{
${ }^{8}$ IAS 16 completes IAS 41
} 
The natural indicators which characterize each biological asset group at the end of the year and the agricultural produce's volume (harvest/hectare, productivity) obtained during the management year.

For each group of biological assets the following information is reveled:

$>$ The determination's principles for the biological assets' value;

$>$ Who determined the biological assets' value - the enterprise or an independent assessor;

$>$ If the biological assets' value was determined at the current value of the cash flows expected to be obtained from these assets, than the discount rate and the number of years for the evaluation of the cash flow will be indicated;

$>$ The existence and the restrictions' sums for the biological assets' propriety, and the biological assets offered as escrow;

$>$ The debts regarding the raise operations for biological assets;

$>$ The actions taken to avoid natural risks, to protect the investments made in biological assets and in the agricultural produce production.

General conclusion: young tree plantation are considered fixed assets from the moment the investment starts at the date of the final reception of the plantation's establishment, not from the moment it goes on fruit. The adherent depreciation is deductible starting with the following month after the final reception.

\section{Bibliography:}

1. Law no. 15 / 24.03.1994 regarding the frozen capital in tangible and intangible assets;

2. G.D. no. 909 / 29.12.1997 regarding the approval of the Methodological Standards of applying Law no. 15/1994 regarding the depreciation of the frozen capital in tangible and intangible assets;

3. P.F.M Order no 1752/17.11.2005 regarding the approval of the accountant regulations in concordance with the European norms;

4. Law no. 571/22.12.2003 regarding the Fiscal code;

5. Law no. 163/01.06.2005 regarding the approval of the Emergency Government Order no. $138 / 2004$ for the modification and the completion of Law no. 571/2003 regarding the Fiscal code;

6. Law no. 244/2002 - the law of the vineyard and the wine in the system of the joint organization of the vine market;

7. Law no. 348/10.07.2003 - the law of the fruit farming; IAS41 - The International Accounting Standard 41 - "Agriculture";

8. The International Accounting Standard 16 - "Tangible Fixed Assets"

9. NAS6 of the Moldova Republic - "The accountancy particularities at agricultural enterprises". 